\title{
Impact of human papillomavirus on head and neck squamous cell cancers in Gabon
}

Ingrid Labouba', Chloé Bertolus ${ }^{2,3}$, Hervé I. Koumakpayii ${ }^{4}$ Ernest Belembaogo ${ }^{4}$, Jérôme Miloundja ${ }^{5}$ and Nicolas Berthet ${ }^{1,6^{*}}$

\begin{abstract}
Head and neck squamous cell cancers are among the most aggressive. Their incidence and mortality rates are relatively lower in Middle Africa than worldwide, but in Gabon, these rates tend to be 2-3 fold higher than in neighboring countries. The main risk factors are alcohol and tobacco consumption. However, in the last decades, there was cumulated evidence that human papillomaviruses were a significant risk factor, particularly for oropharyngeal squamous cell cancer. In Gabon, as elsewhere in Africa, assessment of these 3 risk factors need to be improved to determine their respective role in the development of head and neck squamous cell cancers. The potential differences in alcohol/tobacco consumption habits as well as in infectious ecology between developing and developed countries can make it difficult to transpose current data on this issue. Determining the respective role of alcohol/tobacco consumption and human papillomaviruses in the development of head and neck squamous cell cancers is crucial for the management of these cancers that could become a serious public health issue in Gabon. Human papillomaviruses are not only a risk factor but also a biomarker with promising clinical potential for the follow-up of head and neck squamous cell cancers potentially able to select an adequate treatment. Then, assessing the epidemiological impact of human papillomaviruses in Gabon and in all of Africa would prove useful for the clinical follow-up of head and neck squamous cell cancers, and would also provide essential data to plan a global prevention strategy against head and neck squamous cell cancers due to human papillomaviruses.
\end{abstract}

Keywords: HPV, HNSCC, Oropharynx, Oral cavity, Tobacco, Alcohol, Middle Africa, Biomarker, Vaccination

\section{Background}

Head and neck (excluding nasopharyngeal) cancers, most frequently squamous cell carcinoma, are among the most aggressive worldwide with 599,637 new cases diagnosed and 324,834 associated-deaths in 2012 [1, 2]. We study more specifically oral cavity (OCSCC) and oropharynx (OPSCC) squamous cell carcinomas, still grouped despite the important anatomic and histological distinctions [3]. Their main risk factors, involved in 75$80 \%$ of cases, are tobacco and alcohol $[4,5]$. Human papillomaviruses (HPV) are also a relevant risk factor for head and neck squamous cell carcinomas (HNSCC),

\footnotetext{
* Correspondence: nicolas.berthet@ird.fr

'Department of Zoonosis and Emerging Diseases, Centre International de Recherches Médicales de Franceville - Gabon (CIRMF - GABON), B.P. 769 Franceville, Gabon

${ }^{6}$ Centre National de la Recherche Scientifique, UMR3569, 25 rue du docteurRoux, 75724 Paris, France

Full list of author information is available at the end of the article
}

mainly OPSCC $[6,7]$. The relationship between HNSCC and HPV has been well demonstrated in the United States of America (U.S.A.) and in Europe where up to $60 \%$ of OPSCC could be attributed to HPV [8-10]. This raises the issue of HPV vaccination to prevent HNSCC as well as HPV-induced cervical cancers.

\section{HNSCC risk factors in Middle Africa}

Alcohol and tobacco consumption habits vary according to regions (Table 1) and make it difficult to extrapolate their impact on HNSCC from developed to developing countries. Similarly, differences in the infectious ecology between developed and developing countries complicate transposing the documented involvement of HPV in OPSCC to Africa where the profile of HPV infection is yet to be determined. Furthermore, the impact of HPV, as well as of alcohol and tobacco on HNSCC in Africa, 
Table 1 Alcohol and tobacco consumption in the U.S.A, France, and Gabon [13, 14]

\begin{tabular}{|c|c|c|c|c|c|c|c|c|}
\hline & \multicolumn{3}{|c|}{ Average alcohol consumption ${ }^{a}$} & \multirow[t]{2}{*}{$\begin{array}{l}2010 \text { Alcohol consumption } \\
\text { (drinkers only) }^{\mathrm{a}}\end{array}$} & \multicolumn{2}{|c|}{$\begin{array}{l}2010 \text { prevalence of } \\
\text { binge drinking }{ }^{\mathrm{b}}(\%)\end{array}$} & \multicolumn{2}{|c|}{ 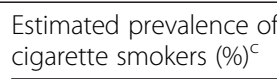 } \\
\hline & $2003-2005$ & $2008-2010$ & $\overline{\text { Change }}$ & & Population & Drinkers only & Current & Daily \\
\hline United States of America & 9.5 & 9.2 & $\rightarrow$ & 13.3 & 16.9 & 24.5 & 18.0 & 14.3 \\
\hline WHO region of Americas & 9.2 & 8.4 & - & & & & & \\
\hline France & 13.4 & 12.2 & $\rightarrow$ & 12.9 & 29.4 & 31 & 22.8 & 20.1 \\
\hline WHO European region & 11.9 & 10.9 & - & & & & & \\
\hline Gabon & 8.8 & 10.9 & $\nearrow$ & 26.5 & 5.3 & 12.9 & 9.0 & 7.0 \\
\hline WHO African region & 6.2 & 6.0 & - & & & & & \\
\hline
\end{tabular}

${ }^{a}$ Alcohol per capita consumption (in liter per capita of pure alcohol) among 15+ population

${ }^{b}$ Consumed at least $60 \mathrm{~g}$ or more of pure alcohol on at least one occasion in the past

'2013 data for U.S.A and France except for Gabon (last update in 2011)

needs to be more extensively studied before defining the best prevention strategy for HNSCC.

In Middle Africa, the incidence of HNSCC (100,000 new cases/year) is lower than the worldwide rate (respectively 4.5 versus 8.0 ), except in Gabon where reported rates are 2-3 fold higher (9.4) (Fig. 1) [1, 11, 12]. However, it is doubtful that these numbers perfectly reflect the true HNSCC rates in Middle Africa and in Gabon. As elsewhere in Africa, cancer registration is not routinely implemented yet in the healthcare institutions managing cancers. Attributing the differences between Gabon and the rest of Middle Africa to a true susceptibility of the Gabonese population or simply to a better screening/registering/ follow-up of HNSCC is a real challenge. In any case, the main issue remains: how to manage HNSCC, which could become a real public health problem, in Gabon?

\section{Tobacco and alcohol consumption in Gabon}

The epidemiology of tobacco and alcohol consumption in Gabon is still poorly documented and assessing their impact represents is a real challenge in developing countries. Tobacco and alcohol prevention programs have induced a significant decrease of HNSCC incidence in developed countries [10]. Similar programs have not been implemented yet in Africa where tobacco and alcohol abuse are increasing $[13,14]$.

The total alcohol consumption in the Gabonese adult population (15+) was $26.50 \mathrm{l}$ per capita of pure alcohol in 2010 (Table 1) compared to 7.901 in 2005 [15]. The trend in Gabon was clearly increasing from 2003 to 2010 unlike in the U.S.A and in France where it remained stable during the same period (Table 1) $[14,15]$. This data, mainly based on import/export economic values, does not take into account indigenous alcoholic products commonly used in local habits. The alcohol consumption in Gabon as well as its true impact on HNSCC could thus be underestimated.

The prevalence of current smokers in Gabon in 2011 was estimated at $15.0 \%$ of men and $2.0 \%$ of women in a population 15 years of age or more (15+) for a global rate of $9.0 \%$ in this population. These rates are lower for daily smokers: global rate of $7.0 \%$ with $12.0 \%$ of men and $1.0 \%$ of women (Table 1). The estimated prevalence of current smokers was respectively 18.0 and $22.8 \%$ in developed countries such as the U.S.A and France in 2013. The rate of smokers was much lower in

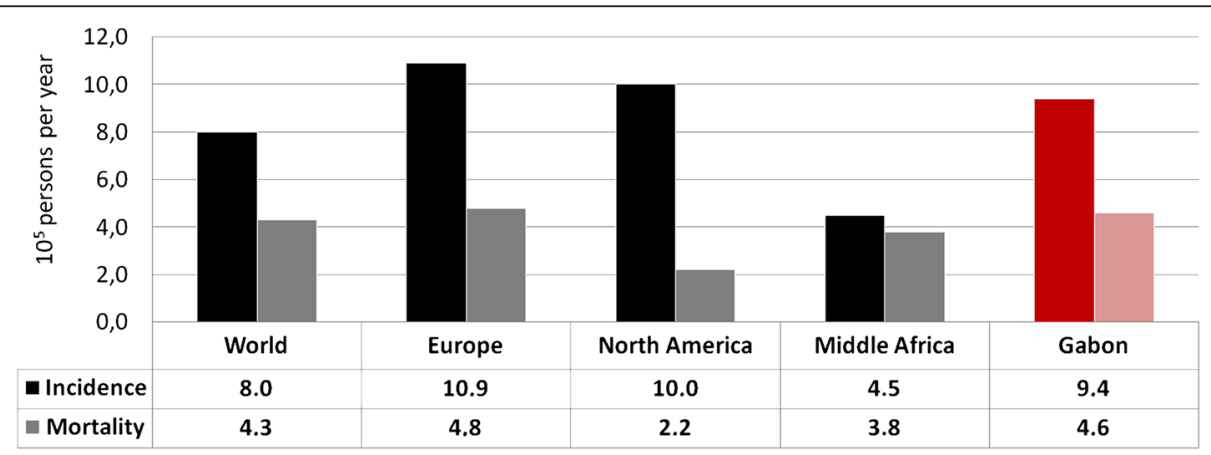

Fig. 1 Estimated age-standardized Incidence (ASIR) and Mortality (ASMR) rates of HNSCC in 2012. Graphic representations and associated numbers $\left(10^{5}\right.$ persons per year) of incidence and mortality rates of all HNSCC worldwide and in various regions. Bars for Gabon, country of interest here, are in red/pink whereas they are black/grey for Europe, Northern America, Middle Africa and worldwide (as World). Dark bars (red for Gabon and black for other regions) represent the incidence rates and the light ones (pink for Gabon and grey for other regions) represent the mortality rates. (Source: GLOBOCAN 2012) [1, 2] 
Gabon (9.0 \%) even though increasing (Table 1) as illustrated by 2 studies on Gabonese teenagers [13]. $10.9 \%$ of the population 14-22 years of age smoked in 2007 [16], compared to $21.5 \%$ in the population $10-19$ years of age in 2011 [17].

The increasing consumption of tobacco and alcohol has become a matter of public health concern in Gabon and requires to be assessed accurately to better understand its impact on HNSCC in the Gabonese population. The example of betel in India and HNSCC perfectly illustrates the importance of local habits. The consumption of betel was documented as a major risk factor for OCSCC in India where tobacco and alcohol consumption is moderate [18].

\section{HPV and cancers in Gabon: screening and vaccination?}

In Africa, most efforts in the prevention of HPV related cancer are focused on CC, associated with HPV infection in $80 \%$ of cases. Cervical cancer (CC) is the most frequently diagnosed and the main cancer-related cause of death in the female population in Africa as well as in Gabon, [4, 11, 12]. Nevertheless, in Gabon, systematic HPV screening has not been integrated yet in the cervical neoplasia detection process. HPV DNA screening relies essentially on PCR with specific/degenerated primer systems or on hybrid capture systems largely used in developed countries. These systems are still too expensive to implement systematic HPV DNA screening in Africa, [19]. However, an immunohistochemical approach could be an affordable alternative with p16 staining as marker of active HPV infection. The public health in Africa and Gabon is currently working on the implementation of efficient programs of early CC screening that would group cervix cytology and HPV detection. Finally, this also should allow for developing prevention strategies by integrating systematic anti-HPV vaccination in the young female population. These efforts to prevent $\mathrm{CC}$ raise the issue of other $\mathrm{HPV}$-attributable cancers such as HNSCC.

OPSCC are the most frequent HPV-attributable HNSCC $[20,21]$. The authors of a recent study on a West African cohort reported that, in Senegal, the low prevalence (3.4 \%) of HPV in HNSCC lesions in 117 patients suggested no significant association with HPV infection, independently of upper airways anatomic sites. However, it is important to underline the small number of OPSCC included (only 4/117 cases) which could lead to underestimate the true impact of HPV in HNSCC [22]. To our knowledge, no team has ever evaluated the cause/effect link between HPV and HNSCC yet, particularly for OCSCC and OPSCC, in Middle Africa including in Gabon. Furthermore, the prevalence of HPV in HNSCC as well as the main HPV types remain undocumented.
Nevertheless, this point is essential to evaluate beforehand the potential impact of anti-HPV vaccination in preventing HNSCC. Bi- and tetravalent vaccines currently under clinical trials have been developed against the main genital HPV types. A new generation nonavalent vaccine could enlarge the anti-HPV spectrum, however, it is still necessary to document whether HPV in the upper airways could be targeted [23]. Furthermore, the HPV status would have an effective prognostic value on the treatment response and on the survival of HNSCC patients [24, 25]. Kreimer et al. reported that even the presence of specific HPV 16/18 antibodies could predict HNSCC development, stressing the potential clinical value of HPV status [26]. Thus, the HPV status appears as a promising tool: i) to plan an adapted prevention strategy, ii) as a biomarker for a better follow-up of HNSCC patients, particularly in non-smokers and non-alcohol consumers [21].

\section{Conclusion}

HNSCC is becoming a matter of public health concern in Gabon. It is necessary to control the main risk factors for their prevention: tobacco, alcohol and HPV. First, it is imperative to determine accurately the rate of these risk factors in Gabon. Therefore, local smoking and drinking habits should be documented to implement adapted programs to raise the awareness of the Gabonese population. Moreover, extending HPV research to the whole Gabonese population is also essential. Numerous ongoing studies are focused on the female population to determine the HPV infection profile in a context of CC. Extending this research to HNSCC would be a valuable move to assess the HPV relative risk. This would ultimately allow for defining the global epidemiological impact of HPV to elaborate an effective vaccine anti-HPV strategy thus preventing the occurrence of HPV-attributable HSNCC.

\section{Abbreviations \\ 15+: Fifteen years and more; HNSCC: Head and neck squamous cell carcinomas; HPV: Human papillomaviruses; OCSCC: Oral cavity squamous cell carcinomas; OPSCC: Oropharyngeal squamous cell carcinomas; U.S.A.: United States of America; WHO: World Health Organization.}

\section{Competing interests}

The authors report no competing interests.

\section{Authors' contribution}

$\| \mathrm{L}, \mathrm{CB}$, and NB drafted the article. HK, MJ, and EB allowed the overview concerning HNSCC in Gabon, despite the absence of published data and helped draft the article. All authors read and approved the final article.

\section{Authors' information}

IL has a Ph.D. in molecular biology with specific experience in transnational cancer research. CB has a M.D specialized in maxillo-facial surgery and her research is focused on factors potentially impacting the rate of HNSCC. NB has a Ph.D. in virology. HK and EB have M.D and are specialized in oncology. HK also has a M.Sc. in molecular biology. MJ has an M.D and is specialized in ENT. 


\section{Acknowledgements}

We thank Andy Andriaina Nkili Meyong for critically reviewing the manuscript. We also thank Heidi Lancon and Dr Pierre-Emmanuel Colle for correcting the English style of the manuscript.

\begin{abstract}
Author details
${ }^{1}$ Department of Zoonosis and Emerging Diseases, Centre International de Recherches Médicales de Franceville - Gabon (CIRMF - GABON), B.P. 769 Franceville, Gabon. ²Department of Maxillofacial surgery, AP-HP, Hôpital Pitié-Salpêtrière, Paris F-75013, France. ${ }^{3}$ UPMC, Université Paris 06, F-75005 Paris, France. ${ }^{4}$ Cancer Institute of Libreville, Laboratory of Tumor Biology, Libreville, Gabon. ${ }^{5}$ Department of ENT, Omar Bongo Ondimba Army Instruction Hospital, Libreville, Gabon. ${ }^{6}$ Centre National de la Recherche Scientifique, UMR3569, 25 rue du docteurRoux, 75724 Paris, France.
\end{abstract}

Received: 17 February 2015 Accepted: 24 September 2015 Published online: 09 November 2015

\section{References}

1. Ferlay J, Soerjomataram I, Dikshit R, Eser S, Mathers C, Rebelo M, et al. Cancer incidence and mortality worldwide: sources, methods and major patterns in GLOBOCAN 2012. Int J Cancer. 2015;136:E359-86. doi:10.1002/ijc.29210.

2. Ferlay J, Soerjomataram I, Ervik M, Dikshit R, Eser S, Mathers C, et al. Cancer Incidence and Mortality Worldwide: IARC CancerBase No. 11: WHO/IARC2012 2012. Report No.: 11.

3. Bertolus C, Goudot P, Gessain A, Berthet N. Clinical relevance of systematic human papillomavirus (HPV) diagnosis in oral squamous cell carcinoma. Infect Agents Cancer. 2012;7:1-2. doi:10.1186/1750-9378-7-13.

4. Jemal A, Bray F, Center MM, Ferlay J, Ward E, Forman D. Global cancer statistics. CA Cancer J Clin. 2011;61:69-90. doi:10.3322/caac.20107.

5. Saman DM. A review of the epidemiology of oral and pharyngeal carcinoma: update. Head Neck Oncol. 2012;4:1-7. doi:10.1186/1758-3284-4-1.

6. D'Souza G, Kreimer AR, Viscidi R, Pawlita M, Fakhry C, Koch WM, et al. Case-control study of human papillomavirus and oropharyngeal cancer. N Engl J Med. 2007:356:1944-56. doi:10.1056/NEJMoa065497.

7. Tran N, Rose BR, O'Brien CJ. Role of human papillomavirus in the etiology of head and neck cancer. Head Neck. 2007;29:64-70. doi:10.1002/hed.20460.

8. Marur S, D'Souza G, Westra WH, Forastiere AA. HPV-associated head and neck cancer: a virus-related cancer epidemic. Lancet Oncol. 2010;11:781-9. doi:10.1016/S1470-2045(10)70017-6.

9. Mehanna H, Olaleye $\mathrm{O}$, Licitra L. Oropharyngeal cancer - is it time to change management according to human papilloma virus status? Curr Opin Otolaryngol Head Neck Surg. 2012;20:120-4. doi:10.1097/MO0.0b013e3283509735.

10. Sturgis EM, Cinciripini PM. Trends in head and neck cancer incidence in relation to smoking prevalence. Cancer. 2007;110:1429-35. doi:10.1002/cncr.22963.

11. Bruni L, Barrionuevo-Rosas L, Albero G, Aldea M, Serrano B, Valencia S, et al. Human Papillomavirus and Related Diseases in Gabon. Summary Report 2015- 03-20. [Data Accessed]: @ICO Information Centre on HPV and Cancer (HPV Information Centre)2015 20 March 2015.

12. Bruni L, Barrionuevo-Rosas L, Albero G, Aldea M, Serrano B, Valencia S, et al, Human Papillomavirus and Related Diseases in the World. Summary Report 2015- 04-08. [Data Accessed]: @ICO Information Centre on HPV and Cancer (HPV Information Centre)2015 8 Avril 2015

13. 2013 W. WHO | WHO report on the global tobacco epidemic 2015. 2015 http://www.who.int/tobacco/global_report/2015/en/.

14. 2014 W. WHO | Global status report on alcohol and health 2014. 2014. http:// www.who.int/substance_abuse/publications/global_alcohol_report/en/.

15. 2015 W. WHO African Region: Gabon statistics summary (2002 - present). In: Global Health Observatory Data Repository. 2015. http://apps.who.int/gho/ data/node.country.country-GAB.

16. Nzouzi N, Piette D. Tabagisme en milieu scolaire secondaire du Gabon Prévalence et facteurs psychosociaux associés. Santé. 2007;17:159-65. doi:10.1684/san.2007.0084.

17. Mimbila-Mayi M, Vierin YN, Biloghe A, Moussavou-Mouyama A. Enquête épidémiologique sur la consommation des substances addictives par les adolescents du Gabon. Santé. 2012;21:149-52. doi:10.1684/san.2011.0253.

18. Znaor A, Brennan P, Gajalakshmi V, Mathew A, Shanta V, Varghese C, et al. Independent and combined effects of tobacco smoking, chewing and alcohol drinking on the risk of oral, pharyngeal and esophageal cancers in Indian men. Int J Cancer. 2003;105:681-6. doi:10.1002/ijc.11114.
19. Fowotade A, M MM. Utilization of Human papillomavirus (HPV) DNA detection for cervical cancer screening in developing countries: a myth or reality. Afr J Microbiol Res. 2013;7(20). doi:10.5897/AJMR12.2186.

20. Combes J-D, Franceschi S. Role of human papillomavirus in nonoropharyngeal head and neck cancers. Oral Oncol. 2014;50:370-9. doi:10.1016/j.oraloncology.2013.11.004

21. Mirghani H, Amen F, Moreau F, Guigay J, Ferchiou M, Melkane AE, et al. Human papilloma virus testing in oropharyngeal squamous cell carcinoma: what the clinician should know. Oral Oncol. 2014;50:1-9. doi:10.1016/ j.oraloncology.2013.10.008.

22. Ndiaye C, Alemany L, Diop Y, Ndiaye N, Diémé M-J, Tous S, et al. The role of human papillomavirus in head and neck cancer in Senegal. Infect Agents Cancer. 2013:8:14. doi:10.1186/1750-9378-8-14.

23. Erickson BK, Landers EE, Huh WK. Update on vaccination clinical trials for HPV related disease. Clin Ther. 2014;36:8-16. doi:10.1016/j.clinthera.2013.11.003.

24. Ang KK, Harris J, Wheeler R, Weber R, Rosenthal DI, Nguyen-Tân PF, et al. Human papillomavirus and survival of patients with oropharyngeal cancer. N Engl J Med. 2010;363:24-35. doi:10.1056/NEJMoa0912217.

25. Lowy DR, Munger K. Prognostic implications of HPV in oropharyngeal cancer. N Engl J Med. 2010;363:82-4. doi:10.1056/NEJMe1003607.

26. Kreimer AR, Johansson M, Waterboer T, Kaaks R, Chang-Claude J, Drogen D et al. Evaluation of Human Papillomavirus Antibodies and Risk of Subsequent Head and Neck Cancer. J Clin Oncol. 2013:JCO.2012.47.738. doi:10.1200/JCO.2012.47.2738

\section{Submit your next manuscript to BioMed Central and take full advantage of:}

- Convenient online submission

- Thorough peer review

- No space constraints or color figure charges

- Immediate publication on acceptance

- Inclusion in PubMed, CAS, Scopus and Google Scholar

- Research which is freely available for redistribution

Submit your manuscript at www.biomedcentral.com/submit
C BioMed Central 